\title{
Manejo de plantas de cobertura na floração e na maturação fisiológica e seu efeito na produtividade do milho
}

\author{
Arminda Moreira de Carvalho(1), Thais Rodrigues Coser ${ }^{(1)}$, Thomaz Adolpho Rein ${ }^{(1)}$, Raíssa de Araujo Dantas ${ }^{(2)}$, \\ Rafael Rodrigues Silva( ${ }^{(2)}$ e Kleberson Worslley Souza(1)

\begin{abstract}
(1)Embrapa Cerrados, BR 020, Km 18, Caixa Postal 08223, CEP 73010-970 Planaltina, DF, Brasil. E-mail: arminda.carvalho@embrapa.br, thacoser@gmail.com, thomaz.rein@embrapa.br, kleberson.souza@embrapa.br (2)Universidade de Brasília, Faculdade de Agronomia e Medicina Veterinária, Campus Darcy Ribeiro, Caixa Postal 04508, CEP 70910-900 Brasília, DF, Brasil. E-mail: rahdantas08@gmail.com, rafaell.r.silva@hotmail.com
\end{abstract}

Resumo - O objetivo deste trabalho foi avaliar o efeito do manejo de plantas de cobertura na floração e na maturação fisiológica sobre a produtividade do milho cultivado em sucessão. $\mathrm{O}$ experimento, em delineamento de blocos ao acaso com parcelas subdivididas, foi realizado em Latossolo Vermelho, em sistema plantio direto, com nove espécies. Foram avaliados: produtividade de matéria seca; tempo de ciclagem dos resíduos vegetais; teores de $\mathrm{N}$ das plantas de cobertura; e produtividade de grãos e teores de $\mathrm{N}$ nas folhas do milho. As espécies Pennisetum glaucum, Mucuna aterrima, Cajanus cajan e Canavalia brasiliensis apresentaram as maiores produtividades de matéria seca na floração. Na maturação fisiológica, Sorghum bicolor, P. glaucum, C. brasiliensis, Crotalaria juncea e C. cajan apresentaram produtividades mais elevadas de fitomassa. Não houve efeito da época de corte e da interação planta de cobertura e época de corte sobre a produtividade do milho. As maiores produtividades de milho foram obtidos após cultivo de Urochloa ruziziensis, C. juncea, C. brasiliensis, C. cajan, P. glaucum e Raphanus sativus, e estão relacionadas ao maior acúmulo de matéria seca e ao menor tempo de ciclagem dos resíduos vegetais das plantas de cobertura.

Termos para indexação: Brachiaria ruziziensis, Canavalia brasiliensis, Pennisetum glaucum, decomposição de resíduos vegetais, plantio direto, ciclagem de nutrientes.

\section{Management of cover crops at flowering and physiological maturity and its effect on maize yield}

\begin{abstract}
The objective of this work was to evaluate the effect of cover crop management at flowering and physiological maturity on maize yield cultivated in succession. The experiment, in a randomized complete block design in a split-plot arrangement, was carried out on a Cerrado Oxisol under no-tillage system, with nine species. The following were evaluated: dry matter yield; turnover time of plant residues; $\mathrm{N}$ contents in cover crop plants; and maize grain yield and N contents in leaves. The species Pennisetum glaucum, Mucuna aterrima, Cajanus cajan, and Canavalia brasiliensis showed the highest dry matter yields during flowering. In physiological maturity, Sorghum bicolor, P. glaucum, C. brasiliensis, Crotalaria juncea, and C. cajan showed higher phytomass contents. There was no effect of mowing time and of the interaction between cover crop species and mowing time on maize yields. The highest maize yields were obtained after planting of Urochloa ruziziensis, C. juncea, C. brasiliensis, C. cajan, P. glaucum, and Raphanus sativus, and are associated with the higher dry matter yield and lower turnover time of the plant residues of the cover crop species.
\end{abstract}

Index terms: Brachiaria ruziziensis, Canavalia brasiliensis, Pennisetum glaucum, plant residue decomposition, no-tillage, nutrient turnover time.

\section{Introdução}

A área cultivada com soja e milho no Brasil é de aproximadamente 45 milhões de hectares, dos quais a maioria é cultivada em sistema plantio direto (Companhia Nacional de Abastecimento, 2013). Porém, para que este sistema seja eficiente, é fundamental um adequado manejo do solo, com uso de práticas conservacionistas mecânicas, edáficas e vegetativas, entre as quais se destaca o uso de plantas de cobertura.

A indicação sistemática de plantas de cobertura, associada a um sistema de rotação e de sucessão de culturas diversificadas para uso em sistema plantio direto no Bioma Cerrado, é uma estratégia para acúmulo de palhada na superfície do solo (Wutke et al., 2014). Entretanto, as condições climáticas nessa região favorecem a decomposição dos resíduos 
vegetais. Nessas condições, estudos mostram que a decomposição da palhada é maior aos 42 dias (Torres et al., 2005) e aos 90 dias após o manejo (Lara-Cabezas et al., 2004). Normalmente, essa decomposição é controlada pela relação $\mathrm{C} / \mathrm{N}$ e pelo teor de lignina, bem como pelo manejo que definirá o tamanho dos fragmentos, o que, em conjunto com a ação do clima, sobretudo temperatura do ar e precipitação (Torres et al., 2008), influencia a atividade dos organismos decompositores.

Entre as vantagens do uso de sistemas apropriados de rotação e de sucessão de culturas, figuram: a estabilidade de produtividade de grãos, pela quebra do ciclo de pragas e de doenças, e pela diminuição da infestação de plantas daninhas; a alternância no padrão de extração e de ciclagem de nutrientes com uso de espécies com diferentes sistemas radiculares; e a manutenção ou a melhoria das condições físicas do solo (Silva et al., 2007a; Lopes et al., 2007). Considerase que a condição ideal é aquela em que o solo tenha sempre uma espécie de planta se desenvolvendo, o que determina alto fluxo de carbono e de energia no sistema solo-planta-atmosfera (Silva et al., 2006). As plantas de cobertura, sobretudo as leguminosas, devem ser recomendadas para associação (rotação, sucessão e consórcio) às culturas, principalmente pelo potencial de adição de $\mathrm{N}$, sendo, também, importantes para o sequestro de C no solo (Sisti et al., 2004).

$\mathrm{O}$ cultivo de milho em sucessão a leguminosas proporciona maior quantidade de $\mathrm{N}$ à cultura, além de melhor aproveitamento do $\mathrm{N}$ proveniente do fertilizante nitrogenado pela planta e maior produtividade de grãos, seja por meio da fixação biológica ou pela ciclagem do $\mathrm{N}$ absorvido das camadas subsuperficiais com a incorporação de biomassa, o que resulta em economia de fertilizantes nitrogenados (Collier et al., 2006; Silva et al., 2006; Albuquerque et al., 2013). Porém, as quantidades de nutrientes liberados pelas gramíneas podem ser iguais ou superiores às acrescentadas pelas leguminosas, dependendo da produção de fitomassa e das concentrações de nitrogênio, lignina, celulose e hemicelulose na parte aérea (Alvarenga et al., 2001; Kliemann et al., 2006; Torres et al., 2008; Teixeira et al., 2010; Carvalho et al., 2011; Carvalho et al., 2012; Doneda et al., 2012). Torres et al. (2008) constataram que o milheto e a crotalária juncea, cultivados no Cerrado sob Latossolo Vermelho, resultaram em maior produtividade de fitomassa seca e acúmulo de
$\mathrm{N}$, aos 110 dias após a semeadura. As maiores taxas de decomposição dessas plantas de cobertura e de liberação de nutrientes ocorreram com os resíduos dessecados aos 42 dias, sendo que os maiores tempos de meia-vida foram observados no período de menor precipitação pluvial.

Fatores bióticos e abióticos - como microrganismos do solo, temperatura do ar e do solo, precipitação pluvial, umidade do solo, quantidade e composição química das plantas de cobertura - influenciam o processo de decomposição e, consequentemente, a ciclagem de nutrientes e a produtividade das culturas subsequentes (Silva et al., 2007b; Carvalho et al., 2008; Carvalho et al., 2009; Carvalho et al., 2011; Talbot \& Treseder, 2012). Entretanto, dependendo da época de corte, da quantidade de matéria seca e de nutrientes das plantas de cobertura, esses fatores podem atuar de forma a acelerar, ou não, o processo de decomposição e a liberação de nutrientes para as culturas (Torres et al., 2008; Pacheco et al., 2011; Carvalho et al., 2012).

$\mathrm{O}$ atraso ou a não dessecação da planta de cobertura com herbicida não seletivo é uma prática de manejo que pode aumentar o tempo de permanência de resíduos de fabáceas na superfície do solo, o que resulta em maior sincronismo entre a liberação de $\mathrm{N}$ de seus resíduos e o período de maior demanda pela planta (Pacheco et al., 2011). Além disso, esse tipo de manejo pode aumentar a produtividade de matéria seca da planta de cobertura, por mantê-la vegetando por um período de tempo mais longo do que no sistema de manejo convencional, com dessecação aos 15-20 dias antes da semeadura do milho, o que fornece maior quantidade de $\mathrm{N}$ ao sistema.

O objetivo deste trabalho foi avaliar o efeito do manejo de plantas de cobertura na floração e na maturação fisiológica sobre a produtividade do milho cultivado em sucessão.

\section{Material e Métodos}

O experimento de milho (Zea mays L.) em sucessão às plantas de cobertura foi implantado em 2005, em área da Embrapa Cerrados, em Planaltina, DF $\left(15^{\circ} 35^{\prime} 30^{\prime \prime} \mathrm{S}, 47^{\circ} 42^{\prime} 30^{\prime \prime} \mathrm{W}\right.$, at $1.000 \mathrm{~m}$ of altitude). Entre 1995 e 2005, a área encontrava-se em pousio. O solo da área experimental é classificado como Latossolo Vermelho distrófico típico, A moderado, caulinítico, fase Cerrado tropical subcaducufólio, relevo suave-ondulado, de textura argilosa (Santos 
et al., 2013). As avaliações foram realizadas no ano agrícola 2009/2010 e 2010/2011. A análise química do solo, coletado na camada de $0-10 \mathrm{~cm}$ de profundidade, ao final do ano agrícola 2010/2011, de acordo com Claessen (1997), apresentou os seguintes resultados: pH 5,9 em H $\mathrm{H}_{2} \mathrm{O} ; 26,3 \mathrm{~g} \mathrm{~kg}^{-1}$ de matéria orgânica; $8,3 \mathrm{mg}$ $\mathrm{dm}^{-3}$ de P-Mehlich-1; 0,07 cmol $_{\mathrm{c}} \mathrm{dm}^{-3}$ de Al; 3,6 cmol $_{\mathrm{c}}$ $\mathrm{dm}^{-3}$ de $\mathrm{Ca}+\mathrm{Mg}$; e $0,2 \mathrm{cmol}_{\mathrm{c}} \mathrm{dm}^{-3}$ de $\mathrm{K}$.

O clima é classificado como tropical estacional, Aw, conforme Köppen, sendo caracterizado por duas estações bem definidas (seca e chuvosa) e pela ocorrência de períodos de estiagem durante a estação chuvosa (Adámoli et al., 1986). Os dados de precipitação pluvial e temperatura média da área experimental estão descritos na Figura 1.

Em abril de 2010, as seguintes espécies vegetais foram semeadas na área, para cobertura do solo: braquiária ruziziensis (Urochloa ruziziensis, syn.: Brachiaria ruziziensis), crotalária juncea (Crotalaria juncea L.), feijão-bravo-do-ceará (Canavalia brasiliensis Mart. ex Benth.), guandu 'BRS mandarim' [Cajanus cajan (L.) Millsp.], milheto 'BR05' [Pennisetum glaucum (L.) R.Br.], mucuna-preta (Mucuna aterrima Merr.), nabo-forrageiro (Raphanus sativus L.), sorgo 'BR 304' [Sorghum bicolor (L.) Moench] e trigo (Triticum aestivum L.). A testemunha foi constituída de parcelas com plantas de ocorrência natural na área (vegetação espontânea). A densidade de plantas foi de: 20 plantas por metro linear, para crotalária juncea, guandu, sorgo, trigo e braquiária ruziziensis; 40 plantas por metro linear, para milheto e nabo-forrageiro; e 10 plantas por metro linear, para feijão-bravo-do-ceará e mucuna-preta. O espaçamento entre linhas de semeadura foi de $0,5 \mathrm{~m}$ para todas as espécies vegetais (Carvalho \& Amabile, 2006).

A semeadura das plantas de cobertura foi realizada diretamente sobre os restos culturais do milho cultivado no ano agrícola anterior, safra 2009/2010. Utilizou-se o delineamento experimental de blocos ao acaso, com parcelas subdivididas e três repetições. As parcelas foram representadas pelas espécies de cobertura $(12 \times 8$ $\mathrm{m})$, e as subparcelas $(12 \times 4 \mathrm{~m})$, pelas épocas de corte na floração e na maturação fisiológica (Tabela 1), o que totalizou $3.420 \mathrm{~m}^{2}$ de área total.

O corte das plantas foi realizado rente ao solo, com duas repetições de $1,0 \mathrm{~m}^{2}$ por subparcela, nos períodos de floração e maturação fisiológica, para determinar a produtividade de matéria seca da parte aérea e obter o material vegetal para avaliação da decomposição. Na colheita das plantas de cobertura, os grãos produzidos foram considerados para avaliação de matéria seca; contudo, o milheto e o sorgo não produziram grãos, em razão do forte ataque de pássaros no campo.

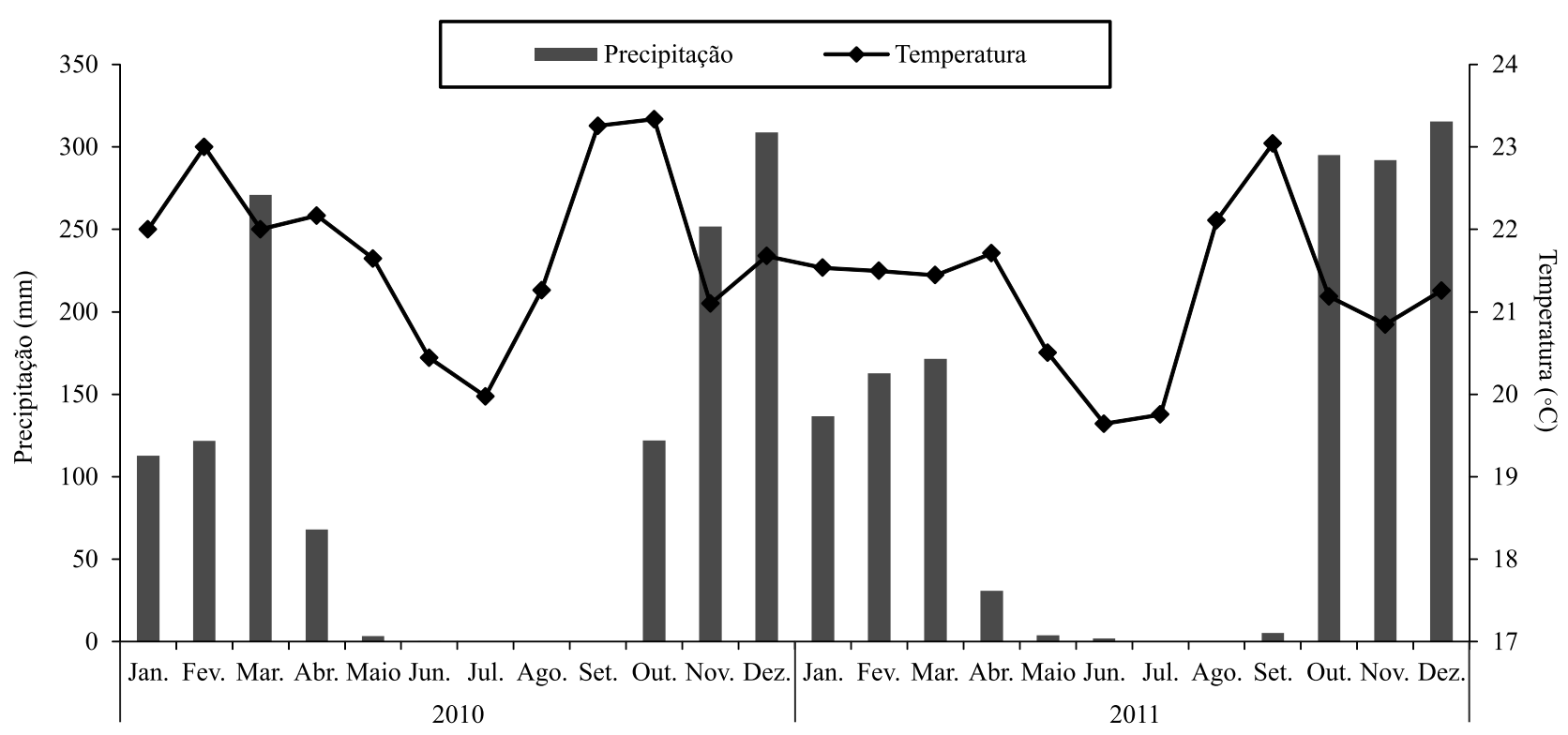

Figura 1. Precipitação pluvial e temperatura média mensais no período de 2010/2011. Dados da Estação Climatológica da Embrapa Cerrados, Planaltina, DF. 
Para a avaliação da decomposição das plantas de cobertura, foram utilizados "litter bags" (sacolas de decomposição de tela de nylon de malha de 2,0 mm) de $20 \times 20 \mathrm{~cm}$, contendo $20 \mathrm{~g}$ do material cortado inclusive sementes do material que sementeou - e seco em estufa, a $65^{\circ} \mathrm{C}$, durante 72 horas (Carvalho et al., 2008). Essas sacolas foram depositadas diretamente na superfície do solo, na estação seca, uma semana após o corte das plantas de cobertura, na floração ou na maturação fisiológica. Mensalmente, após a deposição dos "litter bags" no campo e até a colheita do milho, em 20 de outubro de 2011, foram coletadas três sacolas de cada subparcela, tendo-se determinado as quantidades médias de matéria vegetal remanescente, convertidas em percentagens, em relação aos $20 \mathrm{~g}$ de matéria seca inicial (Carvalho et al., 2008).

Aos resultados, foi ajustado o modelo exponencial, com a percentagem de resíduo remanescente $(\mathrm{Y})$ em função do tempo ( $\mathrm{t}$, dias): $\mathrm{Y}=100 \mathrm{e}^{-\mathrm{kt}}$. Com base na constante de decomposição (k) da equação exponencial, calculou-se o tempo de ciclagem $(\tau)$ do material vegetal $(\tau=1 / \mathrm{k})$, que corresponde ao período (dias) para decomposição de $100 \%$ dos resíduos vegetais (Santos \& Whitford, 1981; Carvalho et al., 2008).

O híbrido simples de milho Pioneer $30 \mathrm{~F} 53 \mathrm{H}$ foi cultivado em sucessão às plantas de cobertura, com semeadura mecanizada em novembro de 2010, com cinco sementes viáveis por metro linear e espaçamento entre linhas de $0,70 \mathrm{~m}$, o que totalizou uma população de 71.500 plantas por hectare. Na semeadura da cultura, foi realizada adubação de manutenção no sulco de plantio, tendo-se utilizado $500 \mathrm{~kg} \mathrm{ha}^{-1}$ da fórmula NPK 4-30-16, acrescida de $2 \mathrm{~kg} \mathrm{ha}^{-1}$ de $\mathrm{Zn}\left(\mathrm{ZnSO}_{4} \cdot 7 \mathrm{H}_{2} \mathrm{O}\right)$ e de $10 \mathrm{~kg} \mathrm{ha}^{-1}$ de FTE BR 12, como fonte de micronutrientes,

Tabela 1. Épocas de corte das plantas de cobertura avaliadas, na floração e na maturação fisiológica (MF) no ano de 2010.

\begin{tabular}{lcc}
\hline Espécie & Floração & MF \\
\hline Braquiária ruziziensis (Urochloa ruziziensis) & $1 / 9$ & $19 / 9$ \\
Crotalária juncea (Crotalaria juncea) & $16 / 6$ & $17 / 8$ \\
Feijão-bravo-do-ceará (Canavalia brasiliensis) & $11 / 8$ & $22 / 9$ \\
Guandu 'BRS mandarim' (Cajanus cajan) & $14 / 8$ & $19 / 9$ \\
Milheto 'BR05' (Pennisetum glaucum) & $10 / 7$ & $25 / 8$ \\
Mucuna-preta (Mucuna aterrima) & $24 / 8$ & $22 / 9$ \\
Nabo forrageiro (Raphanus sativus) & $22 / 6$ & $8 / 8$ \\
Sorgo 'BR 304' (Sorghum bicolor) & $10 / 7$ & $8 / 9$ \\
Trigo (Triticum aestivum) & $20 / 6$ & $23 / 7$ \\
Vegetação espontânea & $6 / 7$ & $27 / 7$ \\
\hline
\end{tabular}

Pesq. agropec. bras., Brasília, v.50, n.7, p.551-561, jul. 2015 DOI: 10.1590/S0100-204X2015000700005 com a seguinte composição química: $3,2 \%$ de $\mathrm{S} ; 1,8 \%$ de $\mathrm{B} ; 0,8 \%$ de $\mathrm{Cu} ; 2,0 \%$ de $\mathrm{Mn} ; 0,1 \%$ de $\mathrm{Mo} ; 9,0 \%$ de $\mathrm{Zn}$; e $1,8 \%$ de $\mathrm{Ca}$. Foram realizadas duas fertilizações com $65 \mathrm{~kg} \mathrm{ha}^{-1}$ de N, em cobertura, tendo como fonte a ureia, aplicadas quando as plantas emitiram o quarto e o oitavo par de folhas, respectivamente, o que totalizou $150 \mathrm{~kg} \mathrm{ha}^{-1}$ de $\mathrm{N}$ de acordo com as recomendações de Sousa \& Lobato (2004).

A amostragem de folhas do milho para determinação do teor de $\mathrm{N}$ foi realizada logo após o aparecimento da inflorescência feminina, tendo-se amostrado a folha abaixo da espiga de 20 plantas em cada subparcela (Sousa \& Lobato, 2004). A concentração de N no tecido foliar foi determinada pelo método de digestão nítrico-perclórica e analisada de acordo com o método semimicro Kjeldahl. Na maturação, em março de 2011, quatro linhas de $4 \mathrm{~m}$ de comprimento foram colhidas em cada subparcela, para quantificação da produtividade de grãos de milho, após a correção da umidade dos grãos para $13 \%$.

A análise de variância permitiu avaliar os efeitos das espécies de plantas de cobertura (parcelas) e dos períodos de corte (subparcelas), bem como da interação entre esses fatores, no teor de $\mathrm{N}$ na folha e na produtividade de grãos do milho, com uso do Proc Mixed do programa SAS, versão 8.1 (SAS Institute, Cary, NC, EUA). Para avaliar o grau de correlação entre as variáveis, utilizouse o coeficiente de correlação linear de Pearson.

\section{Resultados e Discussão}

As espécies milheto, mucuna-preta, guandu e feijão-bravo-do-ceará apresentaram as maiores produtividades de matéria seca na floração, em comparação a braquiária ruziziensis, crotalária juncea, nabo-forrageiro, trigo e vegetação espontânea (Tabela 2). Na maturação fisiológica, o sorgo destacouse significativamente, com maior produção de matéria seca (3,08 $\left.\mathrm{Mg} \mathrm{ha}^{-1}\right)$ do que braquiária ruziziensis, mucuna-preta, nabo-forrageiro, trigo e vegetação espontânea. As produtividades de matéria seca de trigo, nabo-forrageiro, braquiária ruziziensis e vegetação espontânea foram significativamente menores do que os de feijão-bravo-do-ceará, milheto e sorgo, na maturação. Essa menor produtividade de matéria seca na maturação, para várias das espécies avaliadas, pode ser atribuído, em parte, à senescência e à queda de folhas, no caso do nabo-forrageiro e da vegetação 
espontânea, e à diminuição da produção, pelo consumo de grãos por pássaros, no caso do milheto.

Também foram observados baixas produtividades de grãos e a não finalização do ciclo de produção de grãos, para algumas espécies como braquiária ruziziensis, o que reflete a limitada disponibilidade de água no solo com a semeadura na entressafra, no final da estação chuvosa. Produtividades relativamente baixas para essas espécies, quando semeadas na mesma época na região do Cerrado, também são relatadas em outros trabalhos (Burle et al., 1999; Carvalho et al., 2004; Sodré Filho et al., 2004; Torres et al., 2005; Carvalho et al., 2008). No entanto, produtividades duas a três vezes superiores de matéria seca são comumente obtidas com o cultivo dessas espécies no início ou mesmo no final da estação chuvosa, com precipitações excepcionalmente mais elevadas e melhor distribuição de chuvas (Carsky et al., 1990; Boer et al., 2007; Lima et al., 2010; Marcelo et al., 2012).

Os valores de tempo de ciclagem dos resíduos vegetais de feijão-bravo-do-ceará e braquiária ruziziensis foram, em geral, inferiores aos das outras espécies, particularmente na maturação fisiológica (Tabela 2). Na floração, além dessas duas espécies, o nabo-forrageiro e o milheto também apresentaram decomposição mais rápida do que as demais plantas de cobertura. Na decomposição dos resíduos de guandu e sorgo, os tempos de ciclagem foram elevados, tanto no corte realizado na floração, aos 179 e 172 dias, quanto na maturação fisiológica, aos 185 e 222 dias, respectivamente. A crotalária juncea apresentou tempo de ciclagem entre os mais elevados nos dois períodos de corte, aos 238 e 213 dias, respectivamente, na floração e na maturação fisiológica. Esses resultados são explicados pela relação $\mathrm{C} / \mathrm{N}$ e pela composição química em relação ao $\mathrm{C}$ mais recalcitrante do grupo de ligninas. O guandu apresentou concentrações de lignina bem mais elevadas, e o sorgo apresenta relação $\mathrm{C} / \mathrm{N}$ mais elevada do que as do feijão-bravo-do-ceará e da braquiária ruziziensis (Carvalho et al., 2011; 2012). Já o nabo-forrageiro apresentou decomposição significativamente mais rápida quando cortado na floração ( $\tau=96$ dias), em comparação à maturação ( $\tau=200$ dias). Isso pode ser explicado pelo predomínio de folhas sobre talos na primeira época, sendo que, na maturação, o material vegetal é composto basicamente de talos, com concentração de lignina mais elevada em relação à floração (Carvalho et al., 2014; Wutke et al., 2014). De acordo com as avaliações realizadas neste mesmo experimento no ano anterior (Carvalho et al., 2012), a concentração de lignina do nabo-forrageiro, comparada à de $\mathrm{N}$ (lignina/ $\mathrm{N}$ ), é significativamente mais baixa na floração $(0,76)$ do que na maturação $(5,91)$, o que favorece o processo de decomposição.

O nabo-forrageiro e a crotalária juncea apresentaram teores de $\mathrm{N}$ significativamente mais elevados na floração, enquanto o sorgo mostrou o menor valor de concentração desse nutriente (Tabela 3). Na maturação, os maiores teores de $\mathrm{N}$ foram analisados na parte aérea das espécies feijão-bravo-do-ceará, mucuna-preta, crotalária juncea e braquiária ruziziensis.

Tabela 2. Produtividade de matéria seca e tempo de ciclagem dos resíduos das plantas de cobertura avaliadas, com corte na floração e na maturação fisiológica ${ }^{(1)}$.

\begin{tabular}{|c|c|c|c|c|}
\hline \multirow[t]{2}{*}{ Espécie } & \multicolumn{2}{|c|}{ Matéria seca $\left(\mathrm{Mg} \mathrm{ha}^{-1}\right)$} & \multicolumn{2}{|c|}{ Tempo de ciclagem (dias) } \\
\hline & Floração & Maturação & Floração & Maturação \\
\hline Braquiária ruziziensis (Urochloa ruziziensis) & $2,33 \mathrm{cA}$ & $1,84 \mathrm{cA}$ & 123 & 101 \\
\hline Crotalária juncea (Crotalaria juncea) & $2,32 \mathrm{cA}$ & $2,42 \mathrm{abcA}$ & 238 & 213 \\
\hline Feijão-bravo-do-ceará (Canavalia brasiliensis) & $3,30 \mathrm{abA}$ & $2,75 \mathrm{abA}$ & 121 & 119 \\
\hline Guandu 'BRS Mandarim' (Cajanus cajan) & $3,49 \mathrm{abA}$ & $2,37 \mathrm{abcB}$ & 179 & 185 \\
\hline Milheto 'BR05' (Pennisetum glaucum) & $4,07 \mathrm{aA}$ & 2,93abB & 123 & 159 \\
\hline Mucuna-preta (Mucuna aterrima) & $3,92 \mathrm{aA}$ & $2,24 \mathrm{bcB}$ & 141 & 175 \\
\hline Nabo-forrageiro (Raphanus sativus) & $1,89 \mathrm{cdA}$ & $1,78 \mathrm{cA}$ & 96 & 200 \\
\hline Sorgo 'BR 304' (Sorghum bicolor) & $2,82 \mathrm{bcA}$ & $3,08 \mathrm{aA}$ & 172 & 222 \\
\hline Trigo (Triticum aestivum) & $1,25 \mathrm{dA}$ & $0,57 \mathrm{deA}$ & 137 & 164 \\
\hline Vegetação espontânea & $2,28 \mathrm{cA}$ & $1,31 \mathrm{cdB}$ & 132 & 143 \\
\hline $\mathrm{CV}(\%)$ & \multicolumn{2}{|c|}{20,6} & - & - \\
\hline
\end{tabular}

${ }^{(1)}$ Médias seguidas de letras iguais, minúsculas nas colunas e maiúsculas nas linhas, não diferem pelo teste de Tukey-Kramer, a $5 \%$ de probabilidade. 
$\mathrm{Na}$ floração, quanto ao acúmulo de $\mathrm{N}$ na parte aérea, a mucuna-preta, a crotalária juncea e o feijão-bravo-do-ceará apresentaram maiores quantidades do que todas as outras espécies, com exceção do nabo-forrageiro. Nesse mesmo período de manejo, o conteúdo de $\mathrm{N}$ foi menor para sorgo e trigo. $\mathrm{Na}$ maturação, o feijão-bravo-do-ceará apresentou o maior valor de $\mathrm{N}$ acumulado, e o trigo, o menor.

Ao se comparar os períodos de corte, as plantas de cobertura crotalária juncea, milheto, nabo-forrageiro, sorgo, trigo e vegetação espontânea apresentaram teores de $\mathrm{N}$ significativamente superiores na floração, em comparação à maturação. As demais espécies braquiária ruziziensis, feijão-bravo-do-ceará, guandu e mucuna-preta - não apresentaram diferenças significativas quanto aos teores de $\mathrm{N}$ na parte aérea. Ao se analisar o conteúdo de $\mathrm{N}$ na parte aérea, as plantas de cobertura apresentaram os maiores valores com corte na floração, exceto o feijão-bravo-do-ceará e o sorgo, o que indica uma combinação de produtividade de fitomassa e $\mathrm{N}$ mais favorável para a cultura em sucessão. No entanto, a eficiência do uso do $\mathrm{N}$ dependerá da sincronia entre a decomposição dos resíduos vegetais das plantas de cobertura e a absorção do nutriente pela cultura (Torres et al., 2008; Carvalho et al., 2009; Marcelo et al., 2012).

Não houve efeito das plantas de cobertura manejadas nas duas épocas de corte sobre os teores de $\mathrm{N}$ na folha do milho cultivado em sucessão, nos anos agrícolas 2009/2010 e 2010/2011 (Tabela 4), possivelmente em decorrência da aplicação do fertilizante nitrogenado na dose recomendada de $150 \mathrm{~kg} \mathrm{ha}^{-1}$ de $\mathrm{N}$ à cultura. No geral, quando doses adequadas de $\mathrm{N}$ são aplicadas no solo, a maior fração de $\mathrm{N}$ absorvida pelo milho advém do $\mathrm{N}$ do fertilizante, seguido, em ordem decrescente, do solo e dos adubos verdes (Silva et al., 2009). Supõe-se, portanto, que a maior fração do $\mathrm{N}$ dos resíduos vegetais das plantas de cobertura não foi absorvida pelo milho, tendo permanecido no solo, principalmente sob formas orgânicas, e se qualificado como reserva orgânica de nutrientes, sobretudo N (Silva et al., 2006; Silva et al., 2009; Collier et al., 2011).

Não houve efeito da época de corte e nem da interação época de corte e espécies de planta de cobertura na produtividade de grãos do milho. Contudo, o efeito das plantas de cobertura foi significativo em relação a produtividade de grãos, o qual foi alto, tendo variado de $11.666 \mathrm{~kg} \mathrm{ha}^{-1}$ (após trigo) a $12.780 \mathrm{~kg} \mathrm{ha}^{-1}$ (após braquiária ruziziensis) na safra 2010/2011 (Tabela 4). As produtividades na safra 2010/2011 foram superiores para braquiária ruziziensis, crotalária juncea, feijão-bravo-do-ceará e guandu, em comparação a mucuna-preta e trigo. As maiores produtividades de milho estão relacionadas à decomposição mais acelerada dos resíduos vegetais de algumas dessas espécies, as quais são associadas à quantidade de matéria seca produzida. A composição química de plantas de cobertura com baixos teores de lignina, como braquiária ruziziensis e feijão-bravo-do-ceará, e a produção mais elevada de matéria seca devem ter favorecido, não apenas a quantidade de nutrientes, mas, também, a sincronia de liberação à cultura do

Tabela 3. Teor e conteúdo de $\mathrm{N}$ dos resíduos das plantas de cobertura avaliadas, com corte na floração e na maturação fisiológica ${ }^{(1)}$.

\begin{tabular}{lccccc}
\hline Espécie & \multicolumn{2}{c}{ Teor de N (\%) } & & \multicolumn{2}{c}{ Conteúdo de N (kg ha-1) } \\
\cline { 2 - 3 } \cline { 5 - 6 } & Floração & Maturação & & Floração & Maturação \\
\hline Braquiária ruziziensis (Urochloa ruziziensis) & $25,11 \mathrm{bA}$ & $20,95 \mathrm{aA}$ & & $58,35 \mathrm{cA}$ & $38,11 \mathrm{bB}$ \\
Crotalária juncea (Crotalaria juncea) & $39,56 \mathrm{aA}$ & $23,08 \mathrm{aB}$ & & $91,02 \mathrm{aA}$ & $55,91 \mathrm{bB}$ \\
Feijão-bravo-do-ceará (Canavalia brasiliensis) & $24,89 \mathrm{bA}$ & $26,78 \mathrm{aA}$ & & $82,22 \mathrm{aA}$ & $73,29 \mathrm{aA}$ \\
Guandu 'BRS mandarim' (Cajanus cajan) & $20,76 \mathrm{bcA}$ & $18,22 \mathrm{abA}$ & & $72,40 \mathrm{bA}$ & $43,20 \mathrm{bB}$ \\
Milheto 'BR05' (Pennisetum glaucum) & $18,25 \mathrm{cA}$ & $11,27 \mathrm{bB}$ & & $72,54 \mathrm{bA}$ & $32,93 \mathrm{bcB}$ \\
Mucuna-preta (Mucuna aterrima) & $23,93 \mathrm{bA}$ & $25,75 \mathrm{aA}$ & & $93,74 \mathrm{aA}$ & $39,51 \mathrm{bB}$ \\
Nabo-forrageiro (Raphanus sativus) & $43,28 \mathrm{aA}$ & $10,81 \mathrm{bcB}$ & & $79,99 \mathrm{abA}$ & $19,28 \mathrm{cB}$ \\
Sorgo 'BR 304' (Sorghum bicolor) & $10,73 \mathrm{dA}$ & $6,06 \mathrm{cB}$ & & $30,48 \mathrm{dA}$ & $18,60 \mathrm{cA}$ \\
Trigo (Triticum aestivum) & $17,37 \mathrm{cA}$ & $5,47 \mathrm{cB}$ & & $21,63 \mathrm{dA}$ & $3,14 \mathrm{~dB}$ \\
Vegetação espontânea & $26,21 \mathrm{bA}$ & $9,13 \mathrm{bcB}$ & & $58,83 \mathrm{cA}$ & $12,08 \mathrm{cdB}$ \\
\hline CV (\%) & & 14,17 & & & 17,42 \\
\hline
\end{tabular}

${ }^{(1)}$ Médias seguidas de letras iguais, minúsculas nas colunas e maiúsculas nas linhas, não diferem pelo teste de Tukey-Kramer, a 5\% de probabilidade. 
milho. O feijão-bravo-do-ceará, além de se destacar pela maior produção de matéria seca, pelo menor tempo de ciclagem e pelos baixos teores de lignina, apresenta conteúdo de $\mathrm{N}$ elevado $\left(82,22 \mathrm{~kg} \mathrm{ha}^{-1}\right)$ na floração.

Menores produtividades de milho também foram observadas após mucuna-preta, em comparação às demais espécies, no ano agrícola 2008/2009 (Carvalho et al., 2011), e após trigo e vegetação espontânea, no ano subsequente (2009/2010) (Carvalho et al., 2012). Entretanto, resultados diferentes daqueles obtidos nos anos agrícolas anteriores (2008/2009 e 2009/2010) foram verificados para algumas espécies, como guandu, cujas produtividades de milho foram: próximas ao mínimo, quando comparados aos das outras espécies no ano agrícola 2008/2009 (Carvalho et al., 2011); intermediários, no ano agrícola 2009/2010 (Carvalho et al., 2012); e próximas ao máximo, no ano agrícola 2010/2011 (Tabela 4). O guandu é uma leguminosa rica em N (Tabela 3); porém, em razão dos elevados teores de lignina (Carvalho et al., 2011, 2012), apresenta liberação mais lenta de nutrientes (Carvalho et al., 2009, 2011, 2012) e tempo de ciclagem de 179 a 185 dias. Apesar de o trigo apresentar baixos teores de lignina, essa gramínea acumula pouco $\mathrm{N}$, tanto na floração quanto na maturação fisiológica (Tabela 3), o que justifica as baixas produtividades de milho em sucessão (Carvalho et al., 2012). A mucuna-preta, ao contrário, acumula mais $\mathrm{N}$ por ser leguminosa, mas apresenta elevada quantidade de lignina, o que dificulta a sua decomposição para liberação de nutrientes dos seus resíduos vegetais.
A ausência de resposta à mucuna-preta, em relação ao tratamento testemunha (vegetação espontânea), verificada no presente trabalho e também no ano agrícola 2008/2009 (Carvalho et al., 2011), contrasta com os resultados de outros experimentos, em que o milho, sem fertilização nitrogenada, foi cultivado em sucessão a diferentes espécies de leguminosas (Bowen et al., 1988; Carsky et al., 1990; Burle et al., 1999). Segundo Carvalho et al. (2008), o plantio de milho sob palhada de mucuna-preta e sem a aplicação de fertilizante nitrogenado em cobertura pode propiciar aumentos significativos nas produtividades de grãos, bem como acúmulo de $\mathrm{N}$ pelo milho, em razão da elevada capacidade dessa planta de cobertura de acumular $\mathrm{N}$ na parte aérea. No entanto, no presente trabalho, não foram observados aumentos significativos na produtividade de grãos de milho sob palhada de mucuna-preta. Esse resultado pode ser atribuído à decomposição mais lenta dos resíduos vegetais dessa leguminosa, que apresenta elevados teores de lignina (Carvalho et al., 2011, 2012), ou seja, há predomínio de carbono mais recalcitrante, do grupo "aromáticos" (Carvalho et al., 2009, 2014). Assim, não houve liberação do $\mathrm{N}$ em sincronia com a necessidade da cultura de milho, para o seu melhor aproveitamento.

A produção de matéria seca, o conteúdo de $\mathrm{N}$ e a decomposição dos resíduos vegetais influenciaram positivamente a produtividade de grãos, principalmente no caso do feijão-bravo-do-ceará, que se destacou quanto a produtividade mais elevada de matéria seca e ao conteúdo de $\mathrm{N}$ associados à rápida decomposição indicada pelos valores mais baixos

Tabela 4. Teor de $\mathrm{N}$ na folha e produtividade de grãos de milho cultivado em sucessão a diferentes espécies de plantas de cobertura, avaliadas em duas épocas de corte ${ }^{(1)}$.

\begin{tabular}{|c|c|c|c|c|}
\hline \multirow[t]{2}{*}{ Espécie } & \multicolumn{2}{|c|}{ Teor de $\mathrm{N}$ na folha $\left(\mathrm{g} \mathrm{kg}^{-1}\right)$} & \multicolumn{2}{|c|}{ Produtividade $\left(\mathrm{Mg} \mathrm{ha}^{-1}\right)$} \\
\hline & $2009 / 2010$ & $2010 / 2011$ & $2009 / 2010$ & $2010 / 2011$ \\
\hline Braquiária ruziziensis (Urochloa ruziziensis) & $15,71 \mathrm{abc}$ & $26,0 \mathrm{a}$ & 7,64ab & $12,78 \mathrm{a}$ \\
\hline Crotalária juncea (Crotalaria juncea) & $16,99 \mathrm{ab}$ & $27,1 \mathrm{a}$ & $7,72 \mathrm{ab}$ & $12,71 \mathrm{a}$ \\
\hline Feijão-bravo-do-ceará (Canavalia brasiliensis) & $17,68 \mathrm{a}$ & $25,9 \mathrm{a}$ & $7,95 \mathrm{ab}$ & $12,58 \mathrm{ab}$ \\
\hline Guandu 'BRS mandarim' (Cajanus cajan) & $14,99 \mathrm{bc}$ & $24,1 \mathrm{a}$ & $7,32 \mathrm{ab}$ & $12,50 \mathrm{ab}$ \\
\hline Milheto 'BR05' (Pennisetum glaucum) & $15,56 \mathrm{abc}$ & $25,2 \mathrm{a}$ & 7,49ab & $12,13 \mathrm{abc}$ \\
\hline Mucuna-preta (Mucuna aterrima) & $14,52 \mathrm{c}$ & $26,4 \mathrm{a}$ & $7,57 \mathrm{ab}$ & $11,75 \mathrm{c}$ \\
\hline Nabo-forrageiro (Raphanus sativus) & $15,55 \mathrm{bc}$ & $24,8 \mathrm{a}$ & $7,62 \mathrm{ab}$ & $12,28 \mathrm{abc}$ \\
\hline Sorgo 'BR 304' (Sorghum bicolor) & $14,72 \mathrm{bc}$ & $26,2 \mathrm{a}$ & $7,26 \mathrm{~b}$ & $11,96 \mathrm{bc}$ \\
\hline Trigo (Triticum aestivum) & $14,63 \mathrm{c}$ & $25,0 \mathrm{a}$ & $7,23 b$ & $11,67 \mathrm{c}$ \\
\hline Vegetação espontânea & $17,74 \mathrm{a}$ & $24,4 \mathrm{a}$ & $7,32 \mathrm{~b}$ & $11,94 \mathrm{bc}$ \\
\hline$\overline{\mathrm{CV}(\%)}$ & 4,5 & 10,5 & 16,32 & 4,2 \\
\hline
\end{tabular}

${ }^{(1)}$ Médias seguidas de letras iguais, nas colunas, não diferem pelo teste de Tukey-Kramer, a 5\% de probabilidade. 
de tempo de ciclagem, nos dois períodos de corte (Tabela 2). A braquiária ruziziensis, apesar das baixas produtividades de matéria seca, tanto na floração quanto na maturação, apresentou teores mais elevados de $\mathrm{N}$ na maturação e baixos valores de tempo de ciclagem, nos dois períodos de corte, o que pode ter favorecido a ciclagem desse nutriente e, consequentemente, a produtividade do milho.

A correlação linear de Pearson foi realizada tanto para produtividade de grãos de milho, em cada época de manejo das plantas de cobertura (floração e maturação), quanto para produção de matéria seca (MS), tempo de ciclagem (TC), produto (MS x TC) e quociente (MS/ TC); porém, foi significativa apenas para o último, com corte na maturação fisiológica $(\mathrm{r}=0,552 ; \mathrm{GL}=11)$ (Tabela 5). Esse resultado é indicativo de que as produtividades de milho estão diretamente associados à maior ciclagem dos resíduos, expressa pela maior quantidade de resíduos produzida e pela maior taxa de decomposição, isto é, pelo menor tempo de ciclagem.

A associação entre quantidade (produção de matéria seca) e qualidade do material vegetal, ao se considerar a composição química relacionada aos componentes estruturais (lignina, celulose e hemicelulose), à relação $\mathrm{C} / \mathrm{N}$ e à relação lignina/ $\mathrm{N}$, expressos pelo parâmetro meia-vida, explica o processo de decomposição e liberação de nutrientes e, por conseguinte, a produtividade de grãos da cultura (Pacheco et al., 2011; Carvalho et al., 2011, 2012). Carvalho et al. (2012) mostraram que a relação lignina/ $\mathrm{N}$ é o parâmetro que melhor explica o efeito de plantas de cobertura sobre a produtividade de grãos de milho.
Não houve efeito significativo $(\mathrm{p}>0,05)$ da época de corte e da interação época de corte e espécies de plantas de cobertura quanto ao teor de $\mathrm{N}$ na folha de milho e a produtividade de grãos, nos anos agrícolas 2009/2010 e 2010/2011 (Tabela 4). Entretanto, em 2009/2010, houve efeito significativo $(\mathrm{p}>0,05)$ das espécies no teor de $\mathrm{N}$ da folha de milho, com teores mais elevados em sucessão ao feijão-bravo-do-ceará, quando comparado às espécies guandu, mucuna-preta, nabo-forrageiro, sorgo e trigo, o qual também apresentou conteúdos significativamente mais elevados de $N(p>0,05)$ na floração, na safra 2010/2011. O feijão-bravo-do-ceará resultou nas produtividades mais elevadas de milho, nos dois anos agrícolas consecutivos, seguido por braquiária ruziziensis e crotalária juncea. Porém, a mucuna-preta, entre as plantas de cobertura com maiores conteúdos de $\mathrm{N}$ na floração (Tabela 3), resultou nas menores produtividades de grãos, juntamente com o trigo (Tabela 5). Esses resultados são indicativos de que, além do conteúdo de $\mathrm{N}$, a decomposição de resíduos vegetais e a ciclagem de nutrientes contribuem positivamente para a produtividade do milho (Carvalho et al., 2009, 2012). Em 2010/2011, os teores de N na folha de milho foram praticamente o dobro, e as produtividades de grãos foram $5,0 \mathrm{Mg} \mathrm{ha}^{-1}$, em média, superiores aos obtidos no ano agrícola 2009/2010.

Plantas de cobertura, como braquiária ruziziensis e feijão-bravo-do-ceará apresentam decomposição mais acelerada de seus resíduos vegetais (Tabela 2) e promovem maiores produtividades de grãos de milho, em função da maior eficiência na ciclagem de nutrientes; por isso, devem ser associadas a cultura

Tabela 5. Estimativas dos coeficientes de correlação linear de Pearson para produção de matéria seca (MS), tempo de ciclagem (TC), produto (MS x TC), quociente (MS/TC) e produtividade de grãos de milho na floração e na maturação das plantas de cobertura, bem como produtividade média dos grãos de milho.

\begin{tabular}{|c|c|c|c|c|c|c|c|c|c|}
\hline Variáveis $^{(1)}$ & MSF & MSM & TCF & TCM & PMSTCF & PMSTCM & QMSTCF & QMSTCM & PRODME \\
\hline$\overline{\mathrm{MSF}}$ & - & 0,752 & 0,028 & $-0,047$ & 0,780 & 0,503 & 0,831 & 0,659 & 0,056 \\
\hline MSM & & - & 0,265 & 0,243 & 0,728 & 0,854 & 0,541 & 0,736 & 0,349 \\
\hline TCF & & & - & 0,547 & 0,636 & 0,508 & $-0,501$ & $-0,140$ & 0,248 \\
\hline TCM & & & & - & 0,339 & 0,699 & $-0,335$ & $-0,464$ & $-0,237$ \\
\hline PMSTCF & & & & & - & 0,711 & 0,310 & 0,383 & 0,193 \\
\hline PMSTCM & & & & & & - & 0,178 & 0,286 & 0,120 \\
\hline QMSTCF & & & & & & & - & 0,687 & $-0,009$ \\
\hline QMSTCM & & & & & & & & - & 0,552 \\
\hline
\end{tabular}

${ }^{(1)} \mathrm{MSF}$, matéria seca (MS) para corte no florescimento; MSM, MS para corte na maturação; TCF, tempo de ciclagem para corte no florescimento; TCM, tempo de ciclagem para corte na maturação; PMSTCF, produto da matéria seca $\mathrm{x}$ tempo de ciclagem no florescimento; PMSTCM, produto da matéria seca $\mathrm{x}$ tempo de ciclagem na maturação; QMSTCF, quociente da matéria seca / tempo de ciclagem no florescimento; QMSTCM, quociente da matéria seca / tempo de ciclagem na maturação; PRODME, produtividade média de grãos de milho após corte das plantas de cobertura no florescimento e na maturação. 
do milho, que apresenta maior potencial de acúmulo de palhada na superfície do solo. Efeitos benéficos de braquiárias sobre a produtividade de culturas, como milho e soja, já vêm sendo comprovados em sistemas integrados de lavoura-pecuária (Vilela et al., 2011). Como o manejo das plantas de cobertura, seja na floração ou na maturação fisiológica, não mostrou diferenças quanto a produtividade do milho, seu uso fica a critério do produtor, no sentido, principalmente, de minimizar operações agrícolas excedentes. Além disso, deve-se destacar que algumas dessas plantas de cobertura apresentam dormência de sementes, como é o caso da mucuna-preta e do feijão-bravo-do-ceará (Burle et al., 2006); portanto, devem ser manejadas na floração para que não se estabeleçam permanentemente na área e dificultem as práticas agrícolas. Contudo, plantas de cobertura, como sorgo, milheto e trigo, podem ser deixadas até a maturação dos grãos. No caso da braquiária ruziziensis, esta pode permanecer como cobertura na área, caso o objetivo do sistema de produção seja um consórcio para pastejo.

\section{Conclusões}

1. As plantas de cobertura braquiária ruziziensis (Urochloa ruziziensis) e crotalária juncea (Crotalaria juncea), cultivadas no final da estação chuvosa, exercem efeitos positivos sobre a produtividade de grãos de milho, cultivado em sucessão e em sistema plantio direto.

2. O feijão-bravo-do-ceará (Canavalia brasiliensis) destaca-se quanto ao seu conteúdo de nitrogênio.

3. O período de corte das plantas de cobertura no florescimento ou na maturação não tem influência sobre a produtividade de grãos de milho.

\section{Agradecimentos}

Ao Conselho Nacional de Desenvolvimento Científico e Tecnológico (CNPq) e à Coordenação de Aperfeiçoamento de Pessoal de Nível Superior (Capes), pela concessão de bolsas e apoio financeiro.

\section{Referências}

ADÁMOLI, J.; MACEDO, J.; AZEVEDO, L.G.; NETTO, J.M. Caracterização da região dos cerrados. In: GOEDERT, W.J. (Ed.). Solos dos cerrados: tecnologias e estratégias de manejo. Planaltina: Embrapa-CPAC; São Paulo: Nobel, 1986. p.33-74.

ALBUQUERQUE, A.W. de; SANTOS, J.R.; MOURA FILHO, G.; REIS, L.S. Plantas de cobertura e adubação nitrogenada na produção de milho em sistema de plantio direto. Revista Brasileira de Engenharia Agrícola e Ambiental, v.17, p.721-726, 2013. DOI: $10.1590 / \mathrm{S} 1415-43662013000700005$.

ALVARENGA, R.C.; CABEZAS, W.A.L.; CRUZ, J.C.; SANTANA, D.P. Plantas de cobertura de solo para sistema plantio direto. Informe Agropecuário, v.22, p.25-36, 2001.

BOER, C.A.; ASSIS, R.L. de; SILVA, G.P.; BRAZ, A.J.B.P.; BARROSO, A.L. de L.; CARGNELUTTI FILHO, A.; PIRES, F.R. Ciclagem de nutrientes por plantas de cobertura na entressafra em um solo de cerrado. Pesquisa Agropecuária Brasileira, v.42, p.1269-1276, 2007. DOI: 10.1590/S0100-204X2007000900008.

BOWEN, W.T.; QUINTANA, J.O.; PEREIRA, J.; BOULDIN, D.R.; REID, W.S.; LATHWELL, D.J. Screening legume green manures as nitrogen sources to succeeding non-legume crops. Plant and Soil, v.111, p.75-80, 1988. DOI: 10.1007/BF02182039.

BURLE, M.L.; CARVALHO, A.M. de; AMABILE, R.F.; PEREIRA, J. Caracterização das espécies de adubo verde. In: CARVALHO, A.M. de; AMABILE, R.F. (Ed.). Cerrado: adubação verde. Planaltina: Embrapa Cerrados, 2006. p.71-142.

BURLE, M.L.; LATHWELL, D.J.; SUHET, A.R.; BOULDIN, D.R.; BOWEN, W.T.; RESCK, D.V.S. Legume survival during the dry season and its effect on the succeeding maize yield in acid savannah tropical soils. Tropical Agriculture, v.76, p.217-221, 1999.

CARSKY, R.J.; REID, W.S.; SUHET, A.R.; LATHWELL, D.J. Screening legume green manures as nitrogen sources to succeeding non-legume crops. Plant and Soil, v.128, p.275-282, 1990. DOI: 10.1007/BF00011119.

CARVALHO, A.M. de; AMABILE, R.F. Plantas condicionadoras de solo: interações edafoclimáticas, uso e manejo. In: CARVALHO, A.M. de; AMABILE, R.F. (Ed.). Cerrado: adubação verde. Planaltina, DF: Embrapa Cerrados, 2006. p.143-170.

CARVALHO, A.M. de; BUSTAMANTE, M.M.C.; ALCÂNTARA, F.A.; RESCK, I.S.; LEMOS, S.S. Characterization by solid-state CPMAS ${ }^{13} \mathrm{C}$ NMR spectroscopy of decomposing plant residues in conventional and no-tillage systems in central Brazil. Soil and Tillage Research, v.102, p.144-150, 2009. DOI: 10.1016/j. still.2008.08.006.

CARVALHO, A.M. de; BUSTAMANTE, M.M. da C.; SOUSA JUNIOR, J.G. de A.; VIVALDI, L.J. Decomposição de resíduos vegetais em latossolo sob cultivo de milho e plantas de cobertura. Revista Brasileira de Ciência do Solo, v.32, p.2831-2838, 2008. DOI: 10.1590/S0100-06832008000700029.

CARVALHO, A.M. de; COELHO, M.C.; DANTAS, R.A.; FONSECA, O.P.; GUIMARÃES JÚNIOR, R.; FIGUEIREDO, C.C. Chemical composition of cover plants and its effect on maize yield in no-tillage systems in the Brazilian savanna. Crop and Pasture Science, v.63, p.1075-1081, 2012. DOI: 10.1071/ CP12272.

CARVALHO, A.M. de; MARCHÃO, R.L.; BUSTAMANTE, M.M. da C.; ALCÂNTARA, F.A. de; COSER, T.R. Characterization of cover crops by NMR spectroscopy: impacts on soil carbon, nitrogen and phosphorus under tillage regimes. Revista Ciência Agronômica, v.45, p.968-975, 2014. 
CARVALHO, A.M. de; SOUZA, L.L.P. de; GUIMARÃES JÚNIOR, R.; ALVES, P.C.A.C.; VIVALDI, L.J. Cover plants with potential use for crop-livestock integrated systems in the Cerrado region. Pesquisa Agropecuária Brasileira, v.46, p.1200-1205, 2011. DOI: 10.1590/S0100-204X2011001000012.

CARVALHO, M.A.C. de; SORATTO, R.P.; ATHAYDE, M.L.F.; ARF, O.; SÁ, M.E. de. Produtividade do milho em sucessão a adubos verdes no sistema de plantio direto e convencional. Pesquisa Agropecuária Brasileira, v.39, p.47-53, 2004. DOI: 10.1590/S0100-204X2004000100007.

COLLIER, L.S.; CASTRO, D.V.; DIAS NETO, J.J.; BRITO, D.R.; RIBEIRO, P.A. de A. Manejo da adubação nitrogenada para o milho sob palhada de leguminosas em plantio direto em Gurupi, TO. Ciência Rural, v.36, p.1100-1105, 2006. DOI: 10.1590/ S0103-84782006000400009.

COLLIER, L.S.; KIKUCHI, F.Y.; BENÍCIO, L.P.F.; SOUZA, S.A. de. Consórcio e sucessão de milho e feijão-de-porco como alternativa de cultivo sob plantio direto. Pesquisa Agropecuária Tropical, v.41, p.306-313, 2011

COMPANHIA NACIONAL DE ABASTECIMENTO. Acompanhamento da safra brasileira [de] grãos - segundo levantamento - safra 2013/2014. Brasília: Conab, 2013. v.1, n.2, $66 \mathrm{p}$.

CLAESSEN, M.E.C. (Org.). Manual de métodos de análise de solo. 2.ed. Rio de Janeiro: Embrapa-CNPS, 1997. 212p. (Embrapa-CNPS. Documentos, 1).

DONEDA, A.; AITA, C.; GIACOMINI, S.J.; MIOLA, E.C.C.; GIACOMINI, D.A.; SCHIRMANN, J.; GONZATTO, R. Fitomassa e decomposição de resíduos de plantas de cobertura puras e consorciadas. Revista Brasileira de Ciência do Solo, v.36, p.1714-1723, 2012. DOI: 10.1590/S0100-06832012000600005.

KLIEMANN, H.J.; BRAZ, A.J.P.B.; SILVEIRA, P.M. da. Taxa de decomposição de resíduos de espécies de cobertura em latossolo vermelho distroférrico. Pesquisa Agropecuária Tropical, v.36, p.21-28, 2006.

LARA CABEZAS, W.A.R.; ALVES, B.J.R.; CABALLERO, S.S.U.; SANTANA, D.G. Influência da cultura antecessora e da adubação nitrogenada na produtividade de milho em sistema semeadura direta e solo preparado. Ciência Rural, v.34, p.10051013, 2004. DOI: 10.1590/S0103-84782004000400006.

LIMA, J.D.; SAKAI, R.K.; ALDRIGHI, M.; SAKAI, M. Arranjo espacial, densidade e época de semeadura no acúmulo de matéria seca e nutrientes de três adubos verdes. Pesquisa Agropecuária Tropical, v.40, p.531-540, 2010. DOI: 10.1590/ S1983-40632010000400015.

LOPES, R.A.P.; NÓBREGA, L.H.P.; URIBE-OPAZO, M.A.; PRIOR, M.; PEREIRA, J.O. Propriedades físicas de latossolo vermelho distroférrico típico sob sistemas de manejo na sucessão soja-milho no período de três anos. Acta Scientiarum. Agronomy, v.29, p.721-727, 2007. DOI: 10.4025/actasciagron. v29i5.755.

MARCELO, A.V.; CORÁ, J.E.; FERNANDES, C. Sequências de culturas em sistema de semeadura direta. I - Produção de matéria seca e acúmulo de nutrientes. Revista Brasileira de
Ciência do Solo, v.36, p.1553-1567, 2012. DOI: 10.1590/ S0100-06832012000500020.

PACHECO, L.P.; LEANDRO, W.M.; MACHADO, P.L.O. de A.; ASSIS, R.L. de; COBUCCI, T.; MADARI, B.E.; PETTER, F.A. Produção de fitomassa e acúmulo e liberação de nutrientes por plantas de cobertura na safrinha. Pesquisa Agropecuária Brasileira, v.46, p.17-25, 2011. DOI: 10.1590/ S0100-204X2011000100003.

SANTOS, P.F.; WHITFORD, W.G. The efects of microarthropods on litter decomposition in a Chihuazhuan ecosystem. Ecology, v.62, p.654-663, 1981.

SANTOS, H.G. dos; JACOMINE, P.K.T.; ANJOS, L.H.C. dos; OLIVEIRA, V.A. de; LUMBRERAS, J.F.; COELHO, M.R.; ALMEIDA, J.A. de; CUNHA, T.J.F.; OLIVEIRA, J.B. de (Ed.). Sistema brasileiro de classificação de solos. 3.ed. Brasília: Embrapa, 2013. 353p.

SILVA, A.A.; SILVA, P.R.F.; ARGENTA, G.; STRIEDER, M.L.; RAMBO, L. Sistemas de coberturas de solo no inverno e seus efeitos sobre o rendimento de grãos do milho em sucessão. Ciência Rural, v.37, p.928-935, 2007a. DOI: 10.1590/S010384782007000400002

SILVA, E.C. da; MURAOKA, T.; BUZETTI, S.; TRIVELIN, P.C.O. Manejo de nitrogênio no milho sob plantio direto com diferentes plantas de cobertura, em latossolo vermelho. Pesquisa Agropecuária Brasileira, v.41, p.477-486, 2006. DOI: 10.1590/ S0100-204X2006000300015.

SILVA, E.D.; MURAOKA, T.; VILLANUEVA, F.C.A.; ESPINAL, F.S.C. Aproveitamento de nitrogênio pelo milho, em razão da adubação verde, nitrogenada e fosfatada. Pesquisa Agropecuária Brasileira, v.44, p.118-127, 2009. DOI: 10.1590/S0100204X2009000200002.

SILVA, M.B.; KLIEMANN, H.J.; SILVEIRA, P.M.; LANNA, A.C. Atributos biológicos do solo sob influência da cobertura vegetal e do sistema de manejo. Pesquisa Agropecuária Brasileira, v.42, p.1755-1761, 2007b. DOI: 10.1590/S0100-204X2007001200013.

SISTI, C.P.J.; SANTOS, H.P.; KOHHANN, R.; ALVES, B.J.R.; URQUIAGA, S.; BODDEY, R.M. Change in carbon and nitrogen stocks in soil under 13 years of conventional or zero tillage in Southern Brazil. Soil and Tillage Research, v.76, p.39-58, 2004. DOI: 10.1016/j.still.2003.08.007.

SODRÉ FILHO, J.; CARDOSO, A.N.; CARMONA, R.; CARVALHO, A.M. de. Fitomassa e cobertura do solo de culturas de sucessão ao milho na região do cerrado. Pesquisa Agropecuária Brasileira, v.39, p.327-334, 2004. DOI: 10.1590/ S0100-204X2004000400005.

SOUSA, D.M.G. de; LOBATO, E. Adubação com nitrogênio. In: SOUSA, D.M.G. de; LOBATO, E. (Ed.). Cerrado: correção do solo e adubação. 2.ed. Planaltina: Embrapa Cerrados, 2004. p.129-144.

TALBOT, J.M.; TRESEDER, K.K. Interactions among lignin, cellulose, and nitrogen drive litter chemistry-decay relationship. Ecology, v.93, p.345-354, 2012. DOI: 10.1890/11-0843.1.

TEIXEIRA, C.M.; CARVALHO, G.J.; SILVA, C.A.; ANDRADE, M.J.B.; PEREIRA, J.M. Liberação de macronutrientes das palhadas 
de milheto, solteiro e consorciado com feijão-de-porco sob cultivo de feijão. Revista Brasileira de Ciência do Solo, v.34, p.497-505, 2010. DOI: $10.1590 /$ S0100-06832010000200023.

TORRES, J.L.R.; PEREIRA, M.G.; ANDRIOLI, I.; POLIDORO, J.C.; FABIAN, A.J. Decomposição e liberação de nitrogênio de resíduos culturais de plantas de cobertura em um solo de cerrado. Revista Brasileira de Ciências do Solo, v.29, p.609-618, 2005. DOI: 10.1590/S0100-06832005000400013.

TORRES, J.L.R.; PEREIRA, M.G.; FABIAN, A.J. Produção de fitomassa por plantas de cobertura e mineralização de seus resíduos em plantio direto. Pesquisa Agropecuária Brasileira, v.43, p.421-428, 2008. DOI: 10.1590/ S0100-204X2008000300018.
VILELA, L.; MARTHA JUNIOR, G.B.; MACEDO, M.C.M.; MARCHÃO, R.L.; GUIMARÃES JÚNIOR, R.; PULROLNIK, K.; MACIEL, G.A. Sistemas de integração lavoura-pecuária na região do cerrado. Pesquisa Agropecuária Brasileira, v.46, p.1127-1138, 2011. DOI: 10.1590/ S0100-204X2011001000003.

WUTKE, E.B.; CALEGARI, A.; WILDNER, L. do P. Espécies de adubos verdes e plantas de cobertura e recomendações para seu uso. In: LIMA FILHO, O.F. de; AMBROSANO, E.J.; ROSSI, F.; CARLOS, J.A.D. (Ed.). Adubação verde e plantas de cobertura no Brasil: fundamentos e prática. Brasília: Embrapa, 2014. v.1, p.59-168.

$\overline{\text { Recebido em } 28 \text { de novembro de } 2013 \text { e aprovado em } 20 \text { de maio de } 2015}$ 